\title{
Electrospray ionization mass spectrometry characterization of ubiquitous minor lipids and oligosaccharides in milk of the camel (Camelus dromedarius) and their inhibition of oxidative stress in human plasma
}

\author{
Arafa I. Hamed, ${ }^{1,2,3}$ Ridha Ben Said, ${ }^{2,4} \oplus$ Bogdan Kontek, ${ }^{5} \odot$ Abdullah S. Al-Ayed, ${ }^{2}$ Mariusz Kowalczyk, ${ }^{3} \oplus$ \\ Jaroslaw Moldoch, ${ }^{3} \odot$ Wieslaw Oleszek, ${ }^{3}$ Anna Stochmal, ${ }^{3}$ and Beata Olas ${ }^{5 *}$ (1) \\ ${ }_{1}^{1}$ Phytochemistry Laboratory, Department of Botany, Faculty of Science, Aswan University, Aswan 81528, Egypt \\ ${ }^{2}$ Department of Chemistry, College of Science \& Arts at Al-Rass, Qassim University, Al-Rass 58892 Buraidah, Saudi Arabia \\ ${ }^{3}$ Department of Biochemistry and Crop Quality, Institute of Soil Science and Plant Cultivation, State Research Institute, ul. Czartoryskich 8 , \\ 24-100 Pulawy, Poland \\ ${ }^{4}$ Unitè Physico-Chimie des Materiauxa l'Etat Condense UR11ES19, Departement de Chimie, Facultè des Sciences de Tunis Universitè, \\ Tunis EI Manar Campus Universitaire, MANAR II, 2092 Tunis, Tunisia \\ ${ }^{5}$ Department of General Biochemistry, Institute of Biochemistry, Faculty of Biology and Environmental Protection, University of Lodz, \\ Pomorska 141/3, 90-236 Lodz, Poland
}

\section{ABSTRACT}

The aim of this study was to characterize minor lipids in methanol fraction extracted from raw camel milk after loading it on a water-preconditioned short C18 open column and fractionating with a gradient of methanol/water. The C18 column showed high fractionation efficiency of minor lipids, such as glycosphingolipids, lipopolysaccharides, or oligosaccharides, when compared with other constituents, in particular polysaccharides, proteins, and free fatty acids. Liquid chromatography electrospray ionization tandem mass spectrometry in negative ion mode was used to identify 21 new glycosphingolipids, lipopolysaccharides, and oligosaccharides. Electrospray ionization tandem mass spectrometry was qualified to provide relevant data for recognizing the molecular mass, glycosylation sequences, and structure of saccharide moieties for the revealed compounds. The sequence of combinations of one selected lipopolysaccharide, which was considered the backbone of the remaining lipopolysaccharides, was confirmed in a density functional theory study. The obtained results showed that the tested fraction is a rich source of glycosphingolipids, lipopolysaccharides, and oligosaccharides with antioxidant activity.

Key words: camel milk, glycosphingolipid, oligosaccharide, antioxidant, density functional theory

Received March 30, 2019.

Accepted May 24, 2019.

*Corresponding author: beata.olas@biol.uni.lodz.pl

\section{INTRODUCTION}

Milk and milk products are a well-balanced, nutritious food in the human diet. The nutritional quality of milk is attributed to its constituents such as proteins (FAO, 2013), carbohydrates (Newburg, 1996), minerals (Cashman, 2006), concentration of fat-soluble vitamins, fatty acids (Miller et al., 2000; Parodi, 2006; Keszycha et al., 2013), and other solid constituents. Many sources of milk are available, including cows, buffalo, sheep, goats, and camels.

The national economies and food security hinge on the one-hump camel (Camelus dromedarius) in Saudi Arabia and many other countries around the world, especially in Africa and Asia. Camels are a substantial source of food for humans, in particular, meat, milk, and fat (Abdalla et al., 1988; Redwan and Tabll, 2007; Conesa et al., 2008; Agrawal et al., 2009; Alhaj and Al Kanhal, 2010; Sbihi et al., 2013). Since ancient times, camel milk (CM; "white gold" for the desert people) has been a useful drug for the Bedouin tribes of the Arabian, Asian, and African deserts (Alhaider et al., 2011; Asresie and Yusuf, 2014) as a treatment for acute food allergies in children (Abdel Gader and Alhaider, 2016). Camel milk, being rich in phytochemicals, exhibits anti-cancer, antiplatelet, and antithrombotic properties, which are beneficial in the treatment of chronic hepatitis and improve liver function (Sharmanov et al., 1978; Redwan and Tabll, 2007).

Camel milk is a rich source of various unique protective proteins (Conesa et al., 2008; Mona et al., 2010; Kumar et al., 2015; Kula, 2016), including lactoferrin, lysozyme, lactoperoxidase, peptidoglycan recognition protein, $N$-acetyl beta-D-glucosaminidase, IgA, and IgG, which exhibit antiphrastic activity, immunologi- 
cal properties, anti-tumor activity, growth promoting activity, and antibacterial, antiviral, and antifungal properties (Jenssen and Hancock, 2009; Mona et al., 2010; Habib et al., 2013; Kula, 2016).

Glycosphingolipids are sphingolipids that contain a sphingoid long-chain base linked with a fatty acid at the C-2 position, and one or more sugar moieties at the C-1 position (Merrill, 2011). Several constituents of human, cow, bovine, goat, and sheep milk have been reported, including glycosphingolipids (GSL; Puente et al., 1994; Zancada et al., 2010) and oligosaccharides (Zivkovic and Barile, 2011; Albrecht et al., 2014; Smilowitz et al., 2014; Urakami et al., 2018). Human milk contains mainly GSL called cerebrosides with nonhydroxylated fatty acid, whereas bovine milk contains mainly hydroxylated fatty acid (Newburg and Chaturvedi, 1992; Newburg, 1996; Chen et al., 2018). In addition, several studies have shown that goat milk and cow milk contain several GSL (Puente et al., 1994; Zancada et al., 2010) and vitamins (Wu et al., 2017).

Free oligosaccharides are the most abundant solid constituent of milk, apart from lactose and lipids. Several oligosaccharides have been identified in milk from various sources, containing different structural moieties of sugars: lactose, glucose, $\mathrm{N}$-acetyl glucosamine galactose, $N$-acetylgalactosamine, mannose, and fucose (Singh et al., 2016; Srivastava et al., 2016; Urashima et al., 2016; Gangwar et al., 2017; Robinson et al., 2018; Urashima et al., 2018; Tonon et al., 2019). Recently, a new oligosaccharide has been isolated from CM and named medalose (Gangwar et al., 2018). In addition, triacylglycerol molecules in CM (C. dromedarius) have been detected using electrospray ionization (ESI) MS (Haddad et al., 2011).

Recently, ESI in negative mode has proven to be a useful tool for characterization of GSL, lipopolysaccharides (LPS), and oligosaccharides, and gave clear information on the sequence and linkage of their sugar moieties (Pfenninger et al., 2002). Also, it exhibited applicable rapid and sensitive mode for each of the negatively charged, neutral, and acid oligosaccharides without seeking derivatization or adduct formation to aid ionization (Schulz et al., 2002; Thomsson et al., 2000). Electrospray coupled with high resolution liquid chromatography was considered a significant agent, which facilitated resolving the fragmentation pattern of structural isomers found in oligosaccharide mixtures (Pfenninger et al., 2002; Karlsson et al., 2004; Galeotti et al., 2012; Hamed et al., 2016, 2017; Wong et al., 2017; Chen et al., 2018).

Knowledge from the literature and the deprotonated ion peaks as well as fragmentation patterns of the detected compounds showed that these compounds have not previously identified from any milk or other natural resources. The aim of this study was a tentative characterization of novel constituents present in $80 \%$ methanolic portion, which was fractionated from raw CM, such as GSL, LPS, oligosaccharides, and their effect on oxidative damage of human plasma lipids and proteins in vitro. Oxidative stress is associated with many diseases. Thus, the need for naturally occurring antioxidants is crucial. Moreover, the sequence of linkages of one selected lipopolysaccharide, which was considered the backbone of the remaining LPS, was confirmed through a density functional theory (DFT) study.

\section{MATERIALS AND METHODS}

\section{Materials}

Dimethylsulfoxide (DMSO), 5,5'-dithio-bis-(2nitrobenzoic acid), thiobarbituric acid, and hydrogen peroxide $\left(\mathrm{H}_{2} \mathrm{O}_{2}\right)$ were purchased from Sigma (St. Louis, $\mathrm{MO})$. All other reagents were of analytical grade and were provided by commercial suppliers. Stock solution of the tested fraction was made in $50 \%$ DMSO. The final concentration of DMSO in samples (in vitro) was lower than $0.05 \%$ and its effects were determined in all experiments.

\section{Fractionation of Raw CM}

Fractionation of raw CM was achieved through a combination of recent and traditional fractionation procedures (Limon et al., 2014; Oursel et al., 2017; Robinson et al., 2018) and developing innovative extraction methods (Ward, 2009; Hamed et al., 2014, 2016). Raw milk was obtained from a primiparous camel (C. dromedarius) that was fed wild plants by its owner in the Qassim region of the Kingdom of Saudi Arabia. The milk sample $(250 \mathrm{~mL})$ was immediately frozen upon collecting. After $24 \mathrm{~h}$, it was thawed and then centrifuged at 3,500 $\times g$ for 60 min at $4^{\circ} \mathrm{C}(\mathrm{K} 3$ series, Benchtop Centrifuge, Centurion Scientific Ltd., Chichester, UK) to separate hydrophobic portion (lipids) from the hydrophilic one. A sequential filtration was carried out through gauze pads to remove lipids (Limon et al., 2014). Two volumes of pure cold methanol were added to the filtrated portion and incubated at $-30^{\circ} \mathrm{C}$ for 2 $\mathrm{h}$ to precipitate proteins, and subsequently, centrifuged at $3,500 \times g$ and $4^{\circ} \mathrm{C}$ for $30 \mathrm{~min}$. The supernatant was concentrated under reduced pressure to remove the methanol content. The concentrated supernatant (hydrophilic portion) was topped with distilled water up to $250 \mathrm{~mL}$ and fractionated according to our modification 
of the solid phase extraction and fractionation methods for saponins, glucosinolates, and milk oligosaccharides that were previously described (Ward, 2009; Hamed et al., 2014, 2016; Robinson et al., 2018). It was loaded on a flash water-preconditioned short C18 column (10 $\times 15 \mathrm{~cm}$, LiChroprep RP-18, 40-60 $\mu \mathrm{m}$, Merck, Darmstadt, Germany) using tap water suction and eluted with $100 \%$ distilled $\mathrm{H}_{2} \mathrm{O}$ (1.5 L), 40\% (1.5 L), 60\% (1 L), $80 \%$ (1 L), and $100 \%$ methanol, respectively. The $80 \%$ methanol portion was concentrated under reduced pressure and lyophilized using an Eyela Freeze Dryer (FDU-1200, Tokyo Rikakikai Co. Ltd., Tokyo, Japan) to give $200 \mathrm{mg}$ of the $80 \%$ portion. Qualitative analyses of all fractions were carried out using thin layer chromatography (TLC) on $10 \times 20 \mathrm{~cm}$ sheets coated with silica gel $\mathrm{F}_{254}$ (Merck). A mixture of chloroform (HPLC grade, Fisher Chemical, Loughborough, UK), methanol (BDH AnalaR, BDH Chemicals Ltd., Poole, UK), and distilled water $(8: 2: 0.2 \mathrm{vol} / \mathrm{vol} / \mathrm{vol})$ was used as the mobile phase. Visualization of the TLC was carried out by spraying Liebermann-Burchard reagent and heating the TLC plate heater at $100^{\circ} \mathrm{C}$ for 5 min (CAMAG TLC Plate Heater III, Muttenz, Switzerland). The TLC revealed that $80 \%$ portion contains GSL, LPS, and oligosaccharides, and consequently this portion was used for further studies.

\section{HPLC and ESI-MS of Glycosphingolipids, LPS, and Oligosaccharides}

An $80 \%$ methanolic portion of the fractionated raw CM was analyzed using a Thermo LCQ Advantage Max ion trap mass spectrometer. For liquid chromatography separation, a Thermo Surveyor HPLC system and a Waters Symmetry RP-18 column $(5 \mu \mathrm{m}, 2.1 \mathrm{~mm} \times 150$ mm; Waters, Milford, MA) were used. Glycosphingolipid, lipopolysaccharide, and oligosaccharide peaks were detected using a 95-min long linear gradient from 5 to $25 \%$ of mobile phase B $\left[\mathrm{CH}_{3} \mathrm{CN}\right.$ acidified with $0.03 \%$ $\mathrm{HCOOH}$ (vol/vol)] in mobile phase A (HPLC-grade $\mathrm{H}_{2} \mathrm{O}$ acidified with $0.03 \% \mathrm{HCOOH}$ ). The flow rate was $0.4 \mathrm{~mL} / \mathrm{min}$, and column temperature was set at $50^{\circ} \mathrm{C}$.

After moving through the chromatography system, the flow was introduced in the ESI ion source in a negative ion mode $\left([\mathrm{M}-\mathrm{H}]^{-}\right)$, which was adjusted at the following parameters: spray sheath gas $\left(\mathrm{N}_{2}\right)$ flow rate 70 (arbitrary units), capillary voltage $-47 \mathrm{~V}$, tube lens offset $-50 \mathrm{~V}$, voltage $3.9 \mathrm{kV}$, auxiliary gas $\left(\mathrm{N}_{2}\right)$ flow rate 10 (arbitrary units), injection volume $10 \mu \mathrm{L}$, capillary temperature $260^{\circ} \mathrm{C}$. The scan range was $m / z 150$ to 2,000 , and $150 \mathrm{~ms}$ was the maximum injection time with 2 microscans. The LCQ mass spectrometer was run sequentially. Full-scan MS was performed to ac- quire analytical data on anions within the scan range, followed by an MS/MS trial at a normalized collision energy of $35 \%$ to detect the most notable $[\mathrm{M}-\mathrm{H}]^{-}$ion that was obtained in the first step (Hamed et al., 2012, 2016, 2017; Ito et al., 2013; Hsu, 2016).

\section{Human Plasma Isolation}

Fresh human plasma was obtained from medicationfree, regular donors from a blood bank (Lodz, Poland). Plasma was incubated with $80 \%$ aqueous methanol portion of $\mathrm{CM}$ at the final concentrations of 0.5 to 50 $\mu \mathrm{g} / \mathrm{mL}\left(15,30\right.$, and $60 \mathrm{~min}$, at $\left.37^{\circ} \mathrm{C}\right)$ or it was preincubated with $80 \%$ aqueous methanol portion of $\mathrm{CM}$ at 3 final concentrations: $0.5,5$, and $50 \mu \mathrm{g} / \mathrm{mL}(15,30$, and $60 \mathrm{~min}$, at $\left.37^{\circ} \mathrm{C}\right)$, to be then incubated with $2 \mathrm{mM}$ $\mathrm{H}_{2} \mathrm{O}_{2}\left(5 \mathrm{~min}\right.$, at $\left.37^{\circ} \mathrm{C}\right)$.

\section{Lipid Peroxidation Measurement}

Lipid peroxidation was quantified by measuring the concentration of thiobarbituric acid reactive substances (TBARS). The incubation of plasma (control, methanol fraction extracted from raw CM-treated plasma) was stopped by cooling the samples in an ice bath. Samples of plasma were transferred to an equal volume of $20 \%$ ( vol/vol) cold trichloroacetic acid in $0.6 \mathrm{M} \mathrm{HCl}$ and centrifuged at $1,200 \times g$ for $15 \mathrm{~min}$ at $4^{\circ} \mathrm{C}$. One volume of clear supernatant was mixed with 0.2 volume of $0.12 M$ thiobarbituric acid in $0.26 M$ Tris at $\mathrm{pH} 7.0$ and immersed in a boiling water bath for $15 \mathrm{~min}$, then the absorbance at $532 \mathrm{~nm}$ (Spectrophotometer UV/ Vis Helios $\alpha$; Unicam, Cambridge, UK) was measured (Wachowicz, 1984). The TBARS concentration was calculated using the molar extinction coefficient $(\varepsilon=$ $\left.156,000 M^{-1} \cdot \mathrm{cm}^{-1}\right)$.

\section{Thiol Group Determination}

The thiol group content was measured spectrophotometrically (Spectrophotometer UV/Vis Helios $\alpha$ Unicam) with Ellman's reagent. The concentration of thiol groups was calculated using the molar extinction coefficient $\left(\varepsilon=13,600 M^{-1} \cdot \mathrm{cm}^{-1}\right.$; Ando and Steiner, 1973a,b).

\section{DFT Study}

Geometries of the selected compounds and their free correspondent radical were optimized using a DFT with Becke's 3-parameter exchange functional (Becke, 1993). The functional B3LYP (Gill et al., 1992; Becke, 1993) was used applying the $6-31+G(d, p)$ basis set. 


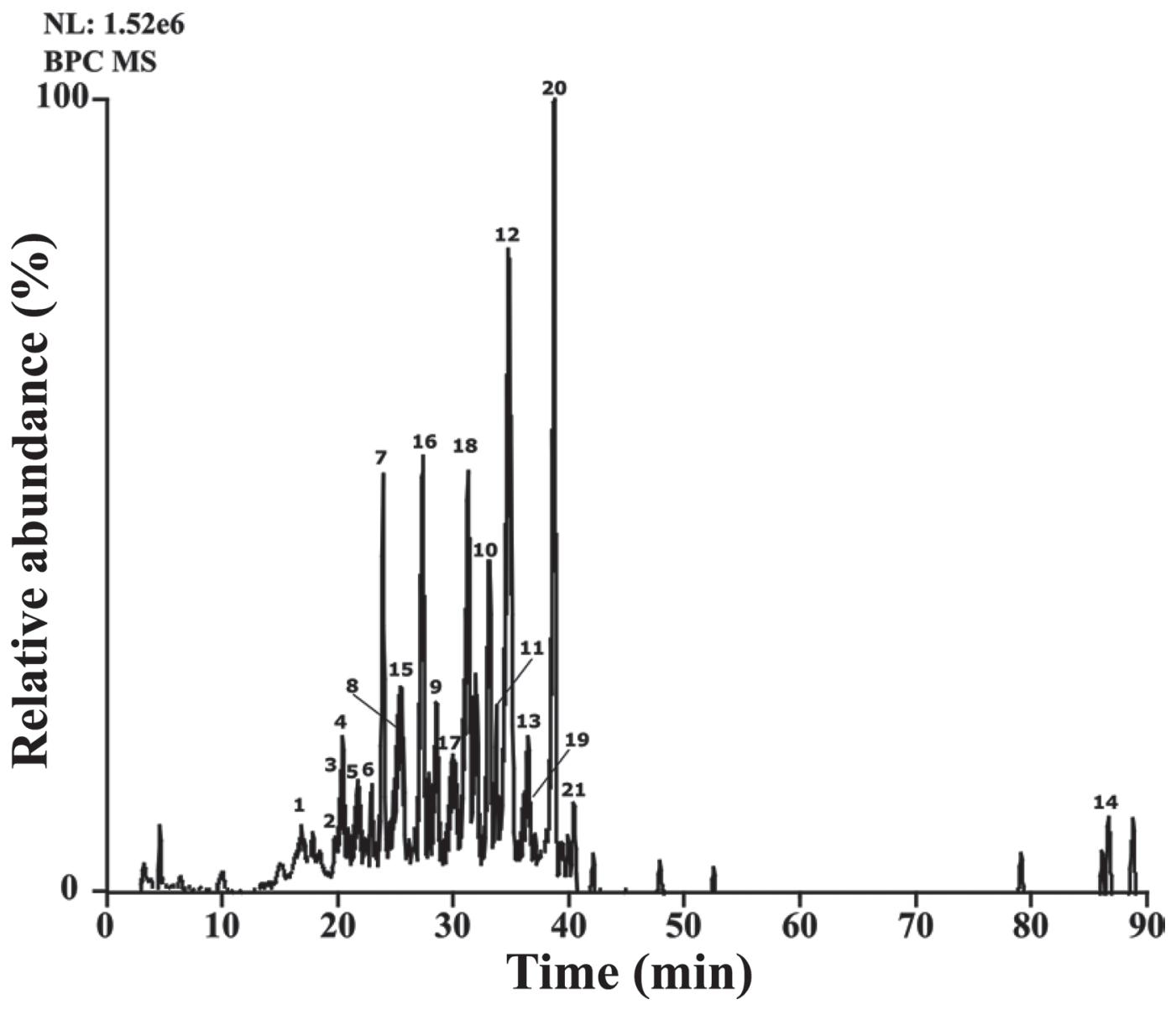

Figure 1. HPLC chromatogram of $80 \%$ methanol portion for camel milk. RT = retention time; NL = normalization level.

\section{Data Analysis}

The statistical analysis (for in vitro model) was carried out by several tests. To eliminate uncertain data, the Q-Dixon test was performed. All the values in this study were expressed as means \pm standard deviation. The statistical analysis was performed with one-way ANOVA for repeated measurements. The statistically significant differences were also assessed applying the paired Student's $t$-test.

\section{RESULTS AND DISCUSSION}

The constituents of $80 \%$ methanolic portion of the fractionated raw $\mathrm{CM}$ after loading onto a short $\mathrm{C} 18$ column were investigated using the liquid chromatography-ESI/MS/MS platform. The ESI-MS/MS in negative ion mode provided adequate data on the molecular mass of minor lipids and the obtained base peak chromatogram showed a relatively complex mixture of GSL, LPS, and oligosaccharides (Figure 1, Table 1).
These compounds were tentatively identified using a parent ion scan of common fragment ions characteristic for the particular class. Ionization conditions and collision energy were optimized for individual molecular species to achieve maximum sensitivity and accuracy. Each target analysis was uniquely identified by a peak ion to a diagnostic product ion mass transition (Domon and Costello, 1988; Karlsson et al., 2004; Ito et al., 2013; Oursel et al., 2017; Wong et al., 2017; Chen et al., 2018).

\section{Identification of Glycosphingolipids}

Glycosphingolipids are composed of 2 portions: hydrophilic sugar and hydrophobic ceramide chains. Ceramides consist of long-chain aliphatic amino alcohol (sphingosine) linked with fatty acyl chain through an amide linkage. The ESI in negative ion mode of CM contains major ions at $m / z 820, m / z 907$, and $m / z 987$, and their fragmentation patterns of peaks indicated the presence of lactosylceramide due to the cleavage 
Hamed et al.: CAMEL MILK AND OXIDATIVE STRESS

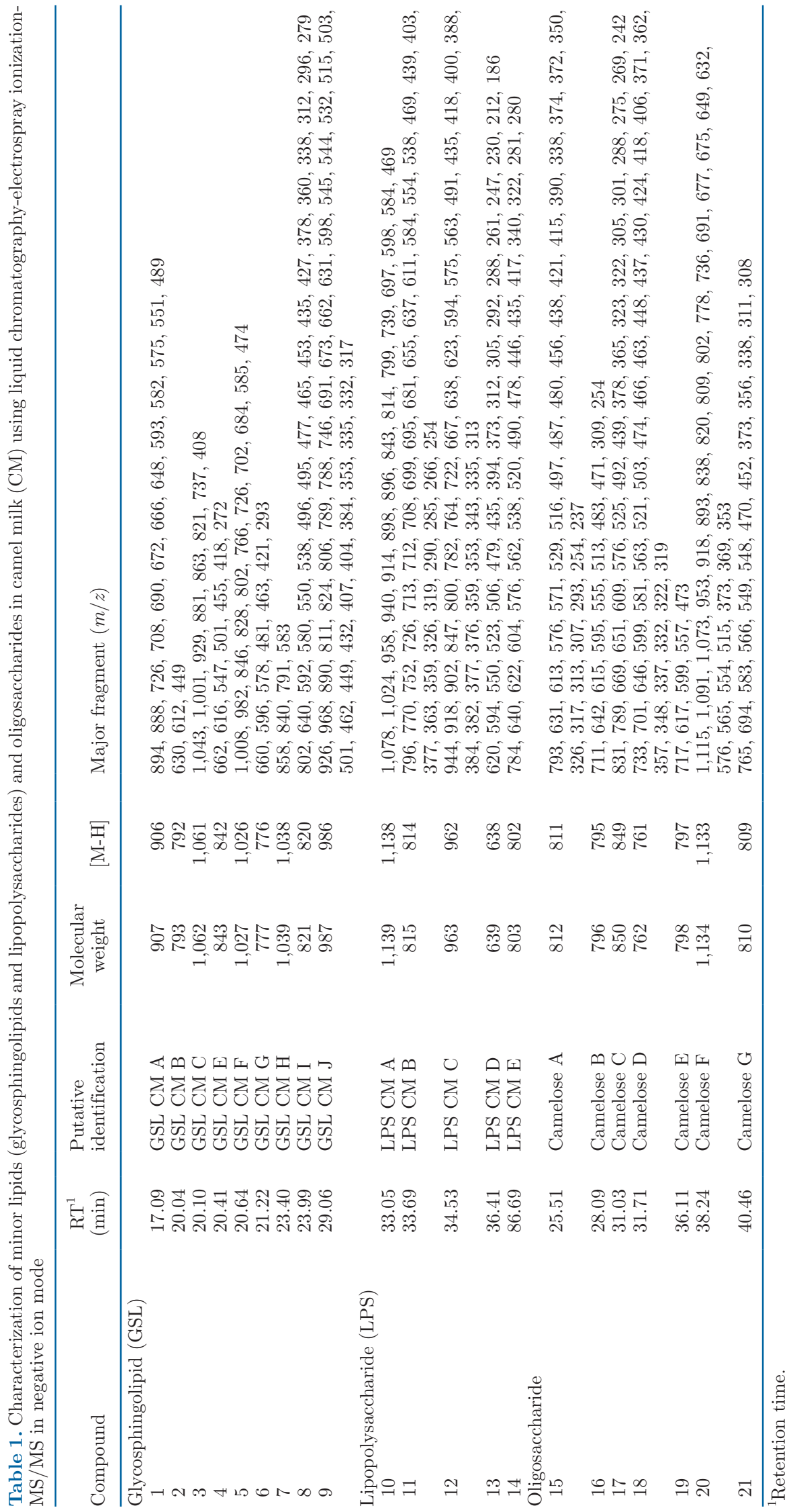


of 324 Da (glucose and galactose moieties). The only difference between them is the ceramide moieties $(\mathrm{m} / \mathrm{z}$ 496, $m / z 582$, and $m / z$ 662; Table 1 and Figure 2). Moreover, the ion peak at $m / z 843$ exhibited only one hexose (162 Da) unit and its ceramide moiety was 680 (Dennis et al., 1992; Farwanah and Kolter, 2012). Several GSL had been previously identified containing one sugar, for example, lutaoside at $m / z 736[\mathrm{M}+\mathrm{Na}]^{+}$ (Poumale et al., 2011) and sarcoehrenoside A at $\mathrm{m} / \mathrm{z}$ $774[\mathrm{M}+\mathrm{Na}]^{+}$(Elkhayat et al., 2012); 2 sugars, for example, petrocerebroside 1 with $\mathrm{m} / z 1032\left[\mathrm{M}+\mathrm{H}^{+}\right.$ and petrocerebroside 2 at $\mathrm{m} / \mathrm{z} 1018[\mathrm{M}+\mathrm{H}]^{+}$(Nelson et al., 2006) or more sugar moieties (Newburg and Chaturvedi, 1992; Christie and Han, 2012a,b), but they differed from our detected compounds in their ceramide moieties.

Herein, the simplified one was selected to be interpenetrated. The ESI-MS of compound 8 showed the presence of an even number deprotonated ion peak at $m / z 820[\mathrm{M}-\mathrm{H}]^{-}$(retention time: $23.99 \mathrm{~min}$; Table 1), which indicated the presence of a nitrogen atom. The product ion at $m / z 802[\mathrm{M}-18-\mathrm{H}]^{-}$was due to the loss of the $\mathrm{H}_{2} \mathrm{O}$ unit, and the product ion at $\mathrm{m} / z 640$ [M$162-\mathrm{H}]^{-}$was attributed to the cleavage of the outer hexose residue (probably galactose moiety, because it is a lactose residue). The product ion at $\mathrm{m} / z 496$ [M-lactose- $\mathrm{H}]^{-}$was due to the cleavage of ceramide residue (Figure 3A). This ceramide residue was confirmed by the presence of 2 diagnostic product ions; one of them at $m / z 297$ revealed the presence of C-18 sphingosine and the second at $m / z 199$ revealed the presence of C-12 fatty acid residue (hydroxyl-lauric acid). Compound 8 was named GSL CM I (lactosylceramide). The previous observation showed that the C-1 (anomoric carbon) of saccharide residues was linked with ceramide moieties. However, the ceramide contains several centers, which gives rise to many possibilities of saccharide residue linkages. And hence, a full optimization of geometry was investigated and Fukui descriptor $\left(f_{i}^{2}\right.$; Morell et al., 2005) was evaluated for 2 selected ceramide residues (ceramide $\mathrm{A}$ and $\mathrm{B}$ ) to elucidate which atom was used to attach with the saccharide residues. Figure 4 showed that the electrophilic center of ceramide $\mathrm{A}$ and $\mathrm{B}$ was concentrated on the $\mathrm{OH}$ group at C-1 of sphingosine residue, whereas the nucleophilic site was mainly localized on the $\mathrm{C}-\mathrm{C}$ double bond in case of ceramide $\mathrm{A}$ and on the coupled free of nitrogen in case of ceramide B. It was clear that both ceramide $\mathrm{A}$ and ceramide B were electrophilic reactants when they reacted with saccharide, and for this reason they reacted with their $\mathrm{OH}$ group at $\mathrm{C}-1$. The fragmentation patterns of the remaining GSL were summarized in Table 1.

\section{Identification of Lipopolysaccharides}

Compound 11 (LPS CM B) showed a deprotonated ion peak at $m / z 814[\mathrm{M}-\mathrm{H}]^{-}$at Rt 33.69 min and the same core of LPS CM D. The presence of diagnostic product ion at $m / z 637[\mathrm{M}-177-\mathrm{H}]^{-}$was due to the cleavage of the outer glucuronic acid or galacturonic acid residue, and this product ion peak resembled the ion peak of LPS CM D. The presence of the product ion at $m / z 770$ [M-44-H] $]^{-}$was due to the loss of $\mathrm{CO}_{2}$ from the glucuronic acid or galacturonic acid moiety. This led to the conclusion that LPS CM B has the structure of LPS CM D as a core backbone. The finding was confirmed by the presence of the product ion at $\mathrm{m} / z 290$ $[\mathrm{M}-203-177-\mathrm{H}]^{-}$due to the presence of 2 conjugated inner fucose residue and the product ion at $\mathrm{m} / \mathrm{z} 611$ $[\mathrm{M}-203-\mathrm{H}]^{-}$was generated by the cleavage of $\mathrm{N}$-acetyl hexosamine. Based on the above mentioned data, the LPS CM B was tentatively similar to compound 13 (LPS CM D), but it exhibited one more hexuronic acid moiety (Figure 2). Compound 10 (LPS CM A) showed ion peak at $m / z 1138[\mathrm{M}-\mathrm{H}]^{-}$at Rt $33.5 \mathrm{~min}$, and the product ion at $m / z 814[\mathrm{M}-324-\mathrm{H}]^{-}$was due to the cleavage of 2 hexose moieties. This indicated that LPS CM A exhibited 2 more hexose residues than LPS CM B.

Compound 12 (LPS CM C) displayed deprotonated ion peak at $m / z 962[\mathrm{M}-\mathrm{H}]^{-}$at $\mathrm{Rt} 34.53 \mathrm{~min}$ and LPS CM D was its core backbone due to the presence of the diagnostic product ion at $m / z 638$ [M-324-H] $]^{-}$as a result of the cleavage of 2 hexose residues (probably lactose residue). The product ion at $m / z 491$ [M-324-147-H] $]^{-}$ was generated by the cleavage of terminal fucose moiety that was conjugated with inner fucose core at $\mathrm{C} 1$. The product ion at $m / z 435[\mathrm{M}-324-203-\mathrm{H}]^{-}$was attributed to the loss of $N$-acetylhexose amine and was equal to the 2 fucoses (292 Da) and caprylic acid residue (143 Da). Two more LPS were summarized in Table 1.

Table 1 and Figure 1 showed deprotonated ion peak at $\mathrm{m} / z 638[\mathrm{M}-\mathrm{H}]^{-}$at $\mathrm{Rt} 36.41 \mathrm{~min}$ for compound 13 (LPS CM D). The diagnostic product ion at $\mathrm{m} / z 435$ [M-203-H $]^{-}$was due to the cleavage of $N$-acetylhexoseamine, which was confirmed by the presence of the product ion at $m / z 186[204-18+\mathrm{H}]^{-}$due to the neutral loss of water $(18 \mathrm{Da})$. The product ion at $\mathrm{m} / z$ $292[\mathrm{M}-203-143-\mathrm{H}]^{-}$was due to the neutral loss of caprylic acid moiety (C8:0), whereas the ion peak at $m / z 292[146+147-\mathrm{H}]^{-}$was characteristic for the splitting of 2 residues of deoxyhexose (fucoses), indicating that the core of compound 13 was fucose, whereas $\mathrm{N}$-acetylhexosamine, caprylic acid, and the second fucose residues were the outer moieties (Figures 2 and $3 \mathrm{~B})$. The presence of the product ion peak at $\mathrm{m} / \mathrm{z}$ 


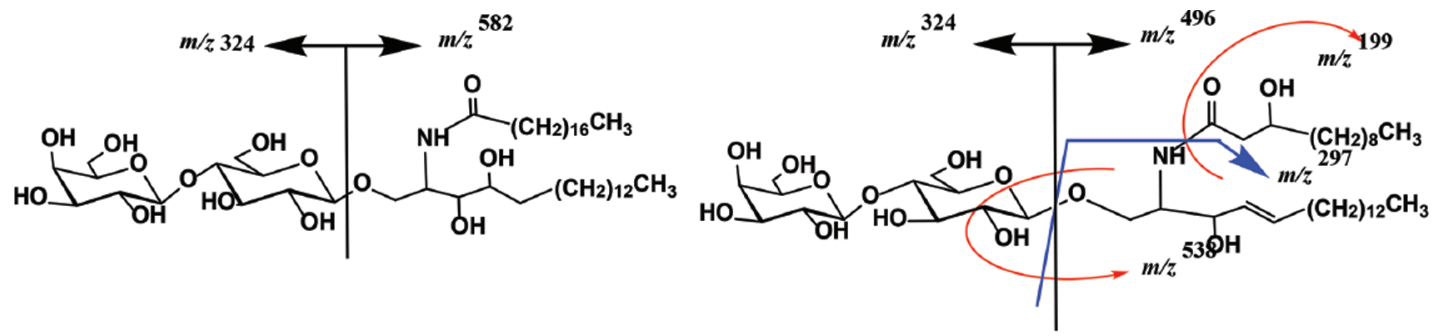

$m / z, 906$ (MW. 907)

$m / z 820$ (MW. 821)
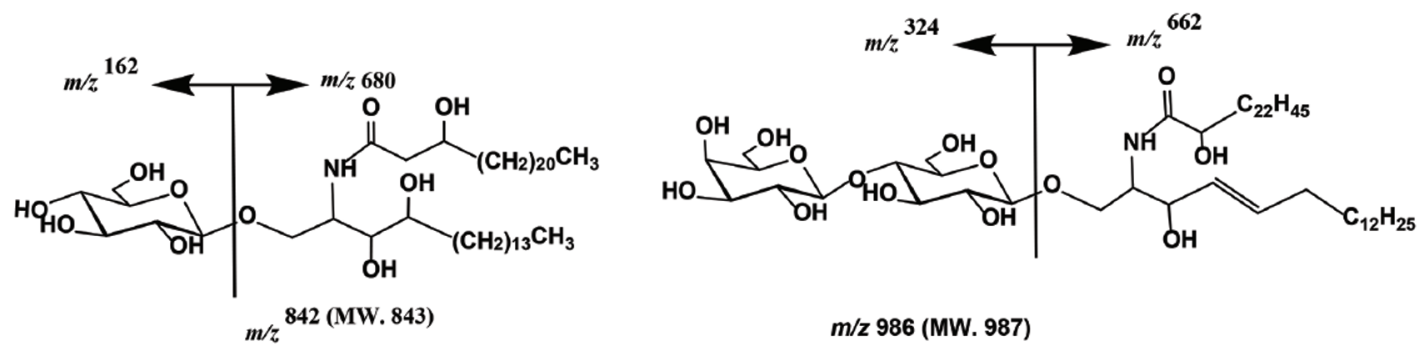

m/z 986 (MW. 987)

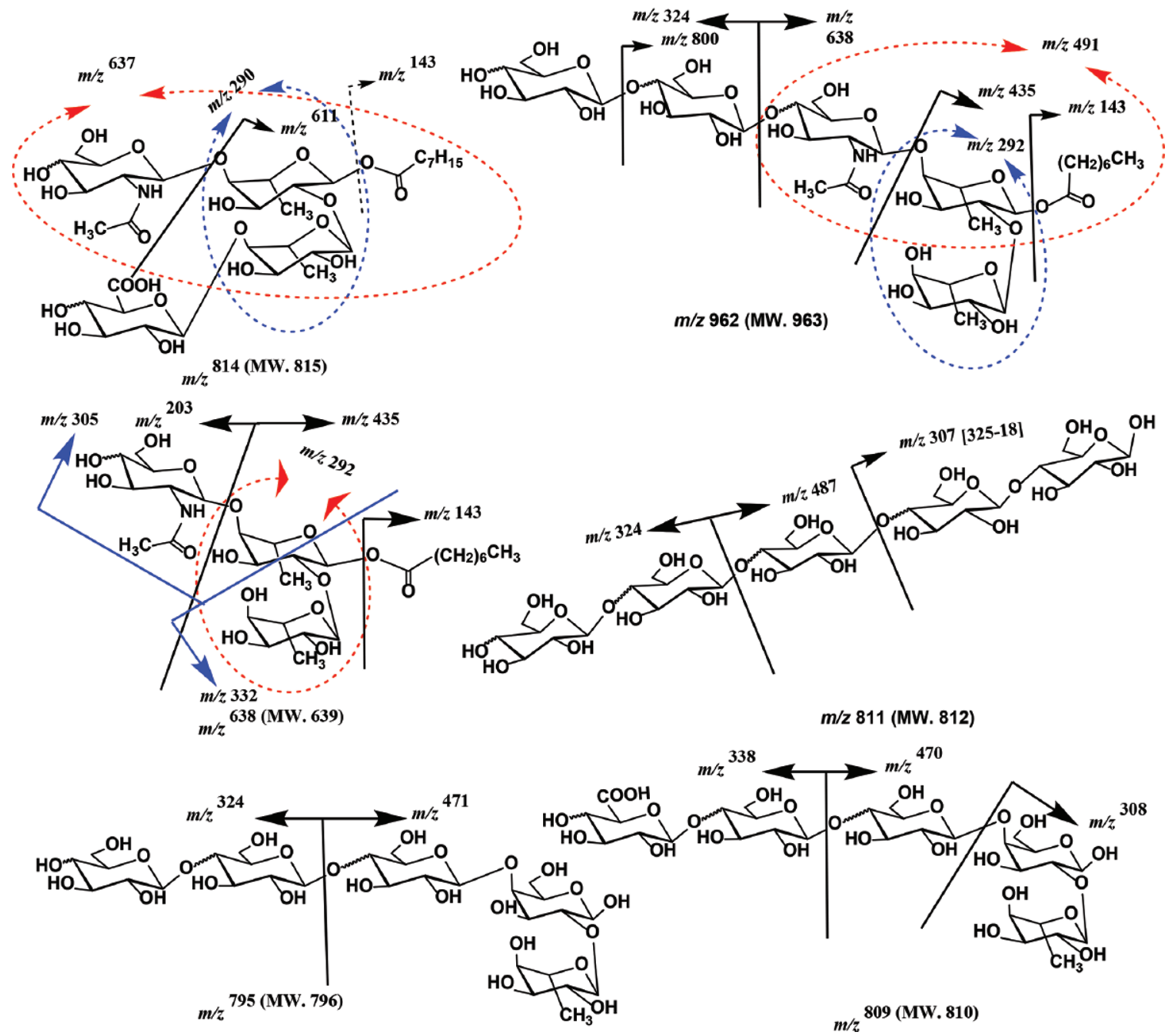

Figure 2. Proposal structure of some selected ion peaks were detected from camel milk. MW = molecular weight. 
NL: 3.01E3 RT: $23.99 \mathrm{~min}$

ESI-MS820@35.00

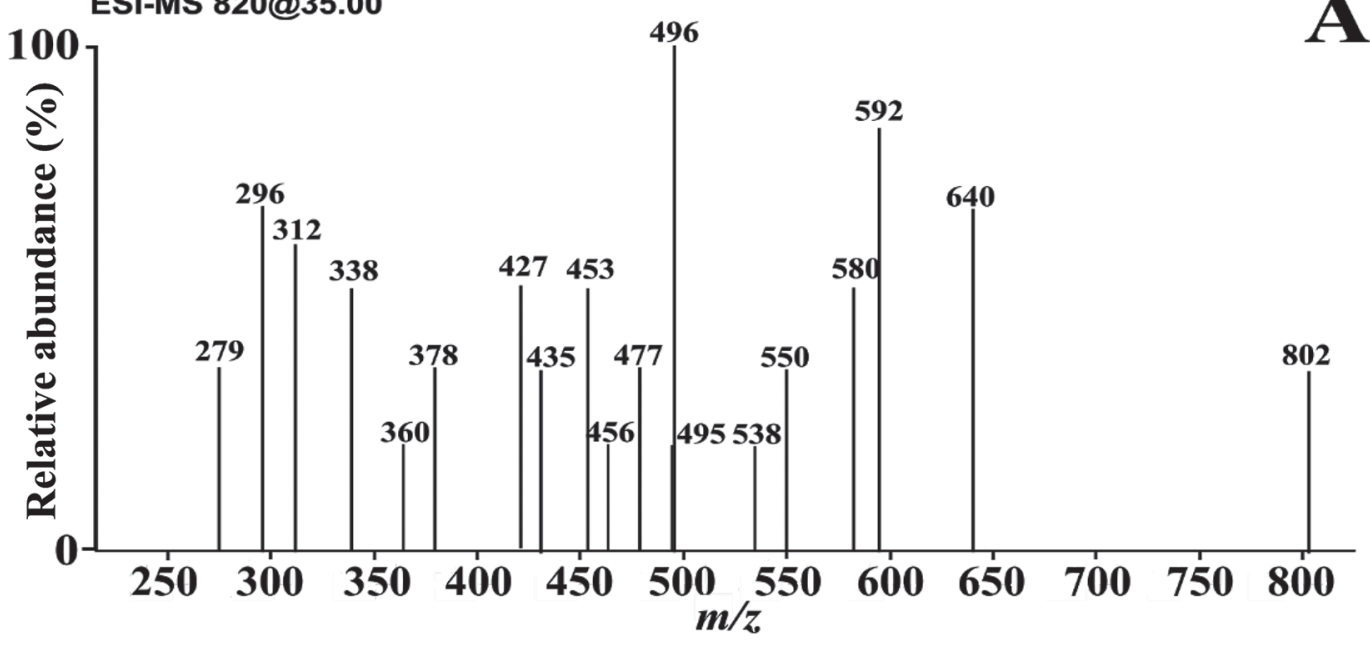

NL: 8.80E3 RT: $36.41 \mathrm{~min}$

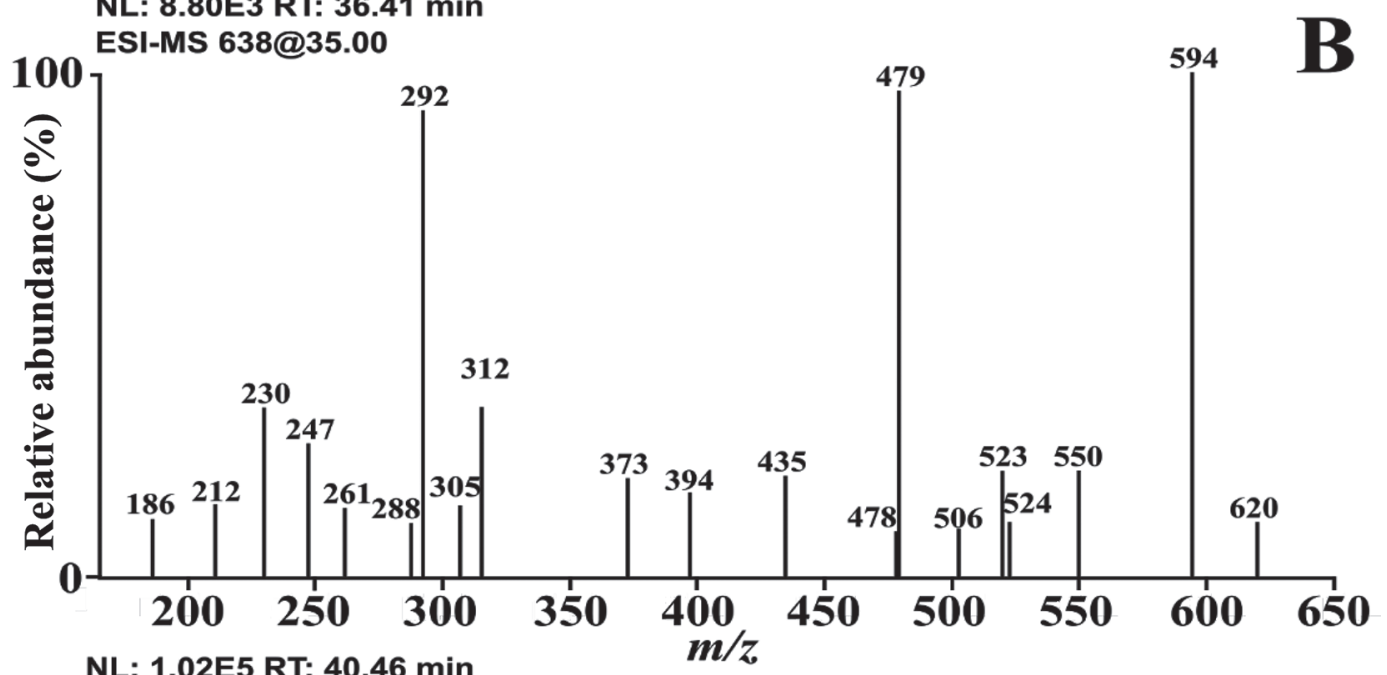

NL: 1.02E5 RT: $40.46 \mathrm{~min}$

ESI-MS 809@35.00

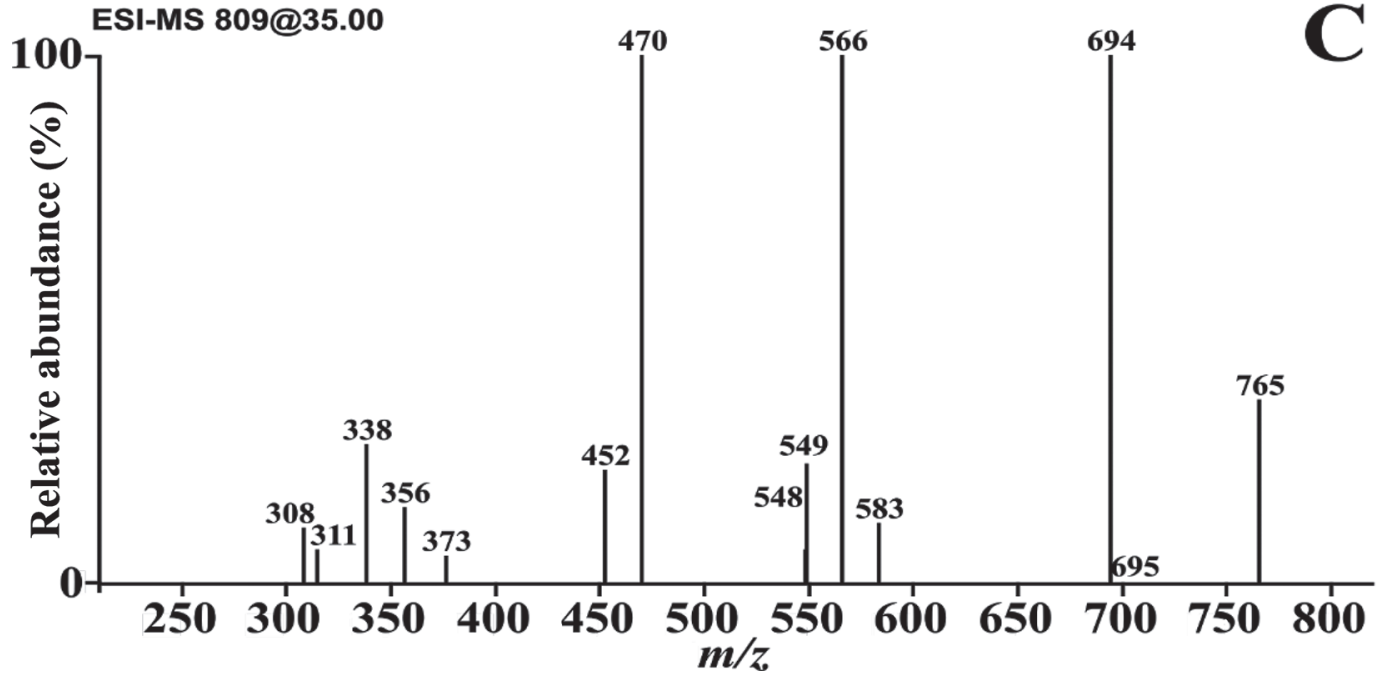

Figure 3. (A) Negative electrospray ionization tandem MS (ESI-MS/MS) of ion peak at $m / z 820$ (glycosphingolipid); (B) negative ESI-MS/ MS of ion peak at $m / z 638$ (lipopolysaccharide); and (C) negative ESI-MS/MS of ion peak at $m / z 809$ (oligosaccharide). RT $=$ retention time; $\mathrm{NL}=$ normalization level. 
$305\left[\mathrm{M}-203-\mathrm{C}_{4} \mathrm{H}_{7} \mathrm{O}_{3}-\mathrm{H}\right]^{-}$proved that the caprylic acid $(m / z 143)$ and fucose moiety were linked to the second fucose (core) at $\mathrm{C} 1$ or $\mathrm{C} 2$. Hence, $\mathrm{N}$-acetylhexose amine will be linked at $\mathrm{C} 3$ or $\mathrm{C} 4$. The DFT study was performed to elucidate the linkage between the core (fucose) and the $\mathrm{N}$-acetylhexose amine. Two isomers were fully optimized using B3LYP/6-31G(d,p); when the $N$-acetylhexose amine was linked to the core in C3, the isomer was noted 13a. Although it was linked at $\mathrm{C} 4$, it was noted as 13b. The linkage of caprylic acid and the outer fucose residue at $\mathrm{C} 1$ at $\mathrm{C} 2$ of the core, respectively, were only investigated (Figure 5). Caprylic acid was previously determined as the one linked with fatty acid constituents of the CM (Konuspayeva et al., 2008).

The optimized geometry was summarized in Figure 5 . The isomer $13 \mathrm{a}$ was less stable than $13 \mathrm{~b}$ by $4.9 \mathrm{kcal} /$ mol due to the presence of steric effect between the fucose residues in 13a. The highest occupied molecular orbitals of the most stable isomer were concentrated in
$\mathrm{N}$-acetylhexose amine moiety and hence compound 13 used this moiety when it acted as a nucleophilic agent. Because the lowest unoccupied molecular orbitals were concentered on the hydroxyl group at $\mathrm{C} 4$ of the outer fucose residue, it was an electrophilic site.

\section{Identification of Oligosaccharides}

The deprotonated ion peaks $[\mathrm{M}-\mathrm{H}]^{-}$, as well as the fragmentation patterns of the detected oligosaccharides had not previously identified from any natural resources (Fukuda et al., 2010; Elkhayat et al., 2012; Sandjo and Kuete, 2013; Alhaj et al., 2013; Albrecht et al., 2014; Urashima et al., 2016; Chen et al., 2018; Gangwar et al., 2018; Robinson et al., 2018; Tonon et al., 2019).

Compound 16 had a precursor ion at $m / z 795[\mathrm{M}-\mathrm{H}]^{-}$ (Rt $28.09 \mathrm{~min}$ ). It showed MS/MS ion characteristic of the product ion peak at $m / z 471[\mathrm{M}-324-\mathrm{H}]^{-}$corresponded to the loss of 2 hexose units (probably lactosyl moiety). The product ion at 309 [M-324-162-H $]^{-}$was<smiles>CCCCC=CC(O)C(CO)NC(=O)CC(O)CCCCCCCCCCCCCCCCCC</smiles>

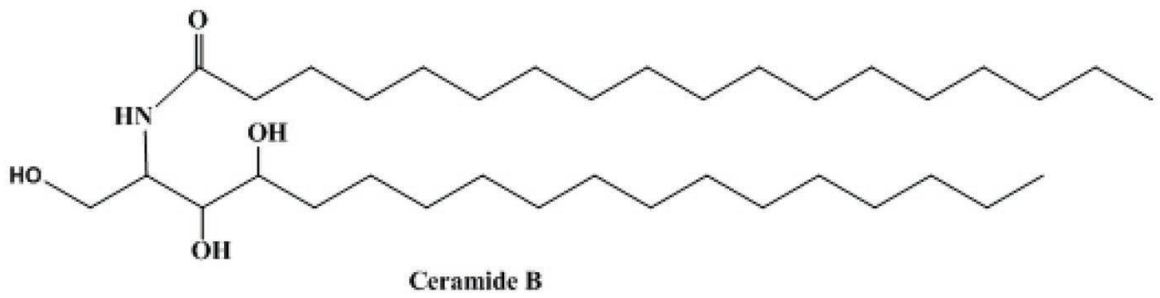

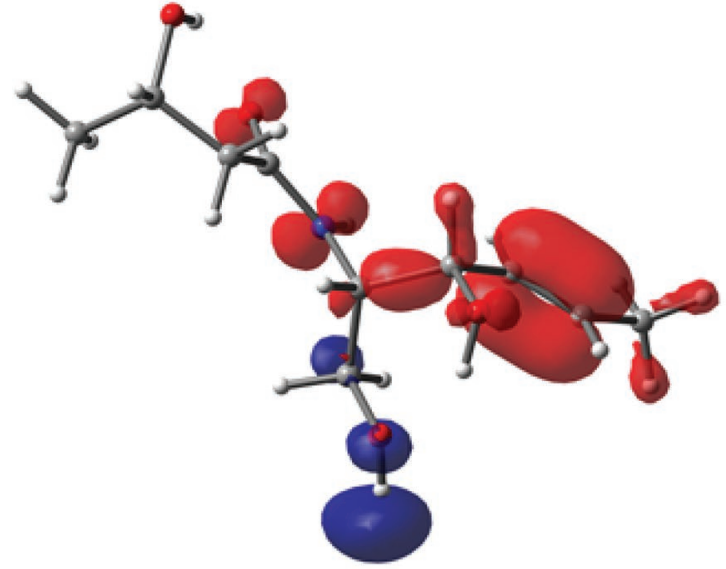

Ceramide A

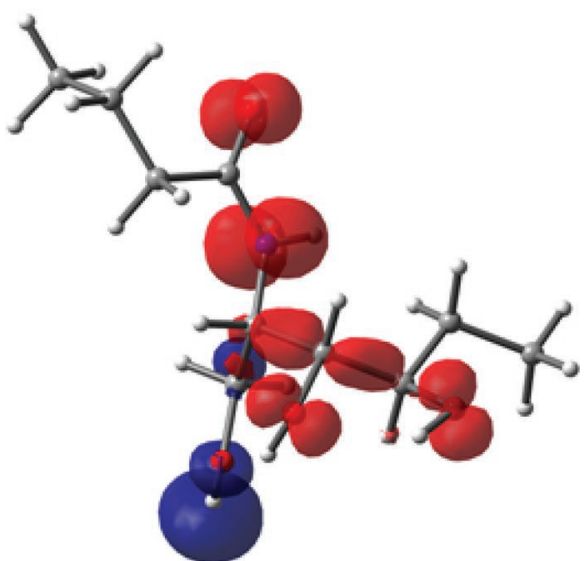

Ceramide B

Figure 4. The $f_{i}^{2}$ isovalues of surfaces (Fukui descriptor) showing nucleophilic (red) and electrophilic (blue) regions of ceramides A and B. 
due to the other hexose unit and the presence of this ion peak indicated the presence of a nonreducing branched end. Therefore, the ion $(m / z 309)$ indicated the disaccharide moiety and was fucose $1 \rightarrow 2$ fucose, which was previously confirmed as the backbone for compound 13 .

The ESI-MS/MS spectrum showed the deprotonated ion peak for compound 20 (camelose $\mathrm{F}$ ) at $\mathrm{m} / z 1,133$ $[\mathrm{M}-\mathrm{H}]^{-}$at Rt $38.24 \mathrm{~min}$. The product ion at $\mathrm{m} / z 1115$ $[\mathrm{M}-18-\mathrm{H}]^{-}$was due to the neutral loss of water and the product ion at $m / z 953[\mathrm{M}-18-162-\mathrm{H}]^{-}$was attributed to the cleavage of 1 hexose moiety. The presence of $\mathrm{m} / \mathrm{z}$ $809[\mathrm{M}-324-\mathrm{H}]^{-}$was due to the cleavage of 2 hexose units (probably lactosyl moiety). The diagnostic product ion at $m / z 677$ [M-324-132-H] $]^{-}$was due to the loss of pentose moiety and ion product was found at $\mathrm{m} / \mathrm{z}$ 515 [M-lactosyl-132-146-16-H $]^{-}$due to the cleavage of fucosyl unit and $16 \mathrm{Da}$ (oxygen). Kangaroo milk contains pentoses instead of lactose, which are not associ-

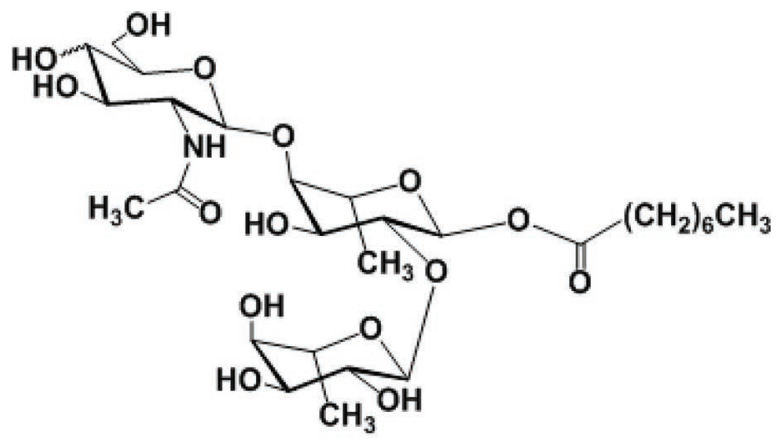

Compound 13

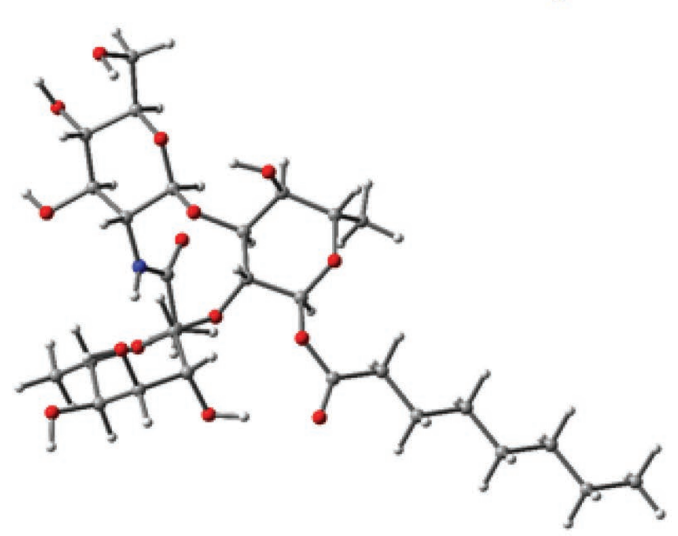

13a

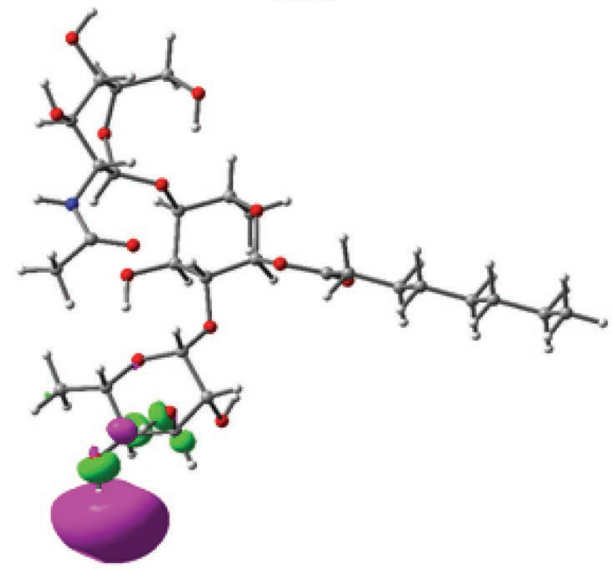

13b-LUMO

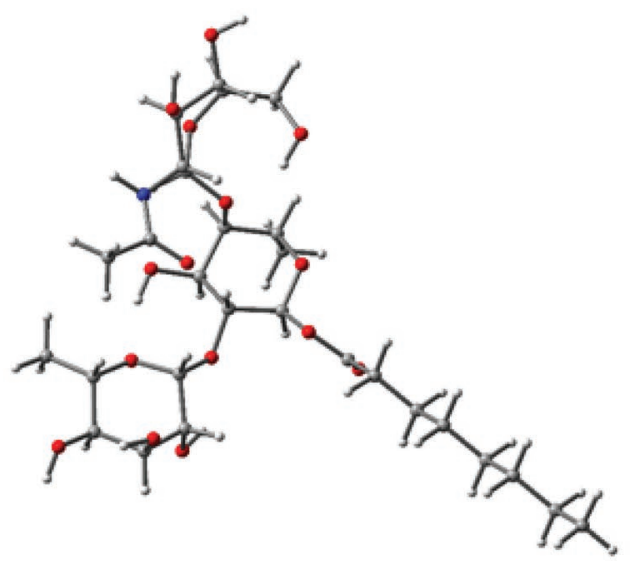

$13 b$

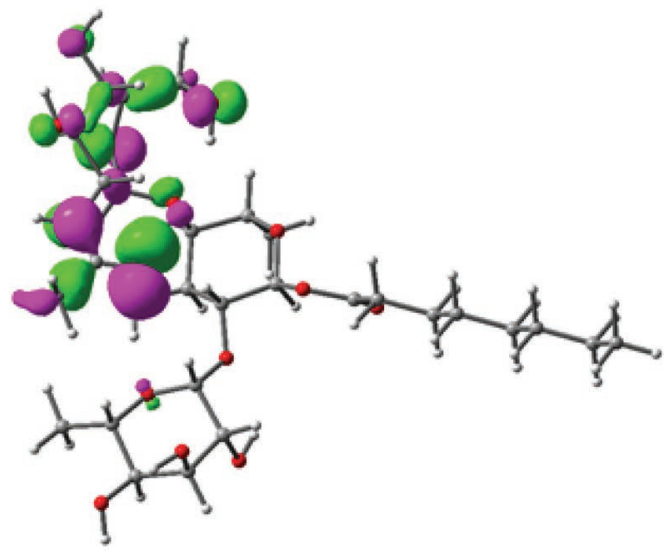

13b-HOMO

Figure 5. Density functional theory (DFT)/B3LYP optimized geometries of compound 13 isomers and frontier orbitals of 13b isomer. LUMO $=$ lowest unoccupied molecular orbitals; HOMO = highest occupied molecular orbitals. 
ated with mammalian milk (Bolliger and Pascoe, 1953; Park and Haenlein, 2006) and this confirmed the presence of conjugated pentose in the CM. The fragment ion with $m / z 353$ (176 Da plus $177 \mathrm{Da}$ ) corresponded to 2 hexuronic acid moieties lacking oxygen (Zhang et al., 2006). Free and conjugated glucuronic acid (hexuronic acid) was recorded in cow milk (Brewington et al., 1973, 1974). Table 1 showed unique fragmentation pattern of camelose $\mathrm{F}$, which arose at certain sugar residues with specific linkages, and these provide an important information on the sequence and linkages. This fragmentation pattern is putatively referred to as the sequence of sugars linkage as follows: hexosyl- $(1 \rightarrow 4)$ hexosyl-( $1 \rightarrow 4$ )-pentosyl-( $1 \rightarrow 4)$-hexosyl-( $1 \rightarrow 4)$-fucosyl$(1 \rightarrow 3)$-hexuronic- $(1 \rightarrow 4)$-hexuronic acid.

The deprotonated ion peak at $m / z 809[\mathrm{M}-\mathrm{H}]^{-}$at Rt 40.46 min for compound 21 (camelose $\mathrm{G}$ ) gave a clear fragmentation pattern, which simplified the interpretation of the remaining oligosaccharides. It gave a diagnostic product ion at $m / z 470[\mathrm{M}-339-\mathrm{H}]^{-}$and was attributed to the loss of hexose and hexuronic acid residue (Brewington et al., 1973, 1974). The presence of the product ion at $m / z 308[\mathrm{M}-339-162-\mathrm{H}]^{-}$was due to the cleavage of inner hexose molecule, which may be glucose or galactose. The presence of the product ion at $\mathrm{m} / z 308$ (equal to 162 and $146 \mathrm{Da}$ ) indicated the presence of fucose residue on hexose moiety (Pfenninger et al., 2002). The presence of the ion $m / z 308(146+162)$ indicated the linkage of branched with nonreducing end, corresponding to the disaccharide, which was Fuc $1 \rightarrow 3$ Fuc or Fuc $1 \rightarrow 2$ Fuc. This was tentatively identified as the hexuronic- $(1 \rightarrow 4)$-hexosyl-( $1 \rightarrow 4)$-hexosyl$(1 \rightarrow 4)$-fucosyl-( $1 \rightarrow 2)$-fucosyl (camelose $\mathrm{G}$ ) (Figures 2 and $3 \mathrm{C})$.

The ESI-MS/MS showed the deprotonated ion peak at $m / z 795[\mathrm{M}-\mathrm{H}]^{-}$at Rt $28.09 \mathrm{~min}$ for compound 16 (camelose B), whose $m / z$ was 14 Da less than compound 21 (camelose $\mathrm{G}$ ) and this difference was due to the presence of hexuronic acid in compound 21 instead of hexose moiety in compound 16. The ESI-MS/MS analysis showed a product ion at $m / z 471$ [M-324-H] $]^{-}$ due to cleavage of 2 outer hexose units (lactose moiety). This ion peak $(m / z 471)$ consists of 1 hexose unit (162 $\mathrm{Da})$ and branched fucose moieties $(146+162 \mathrm{Da})$. Compound 16 was tentatively named the hexosyl- $(1 \rightarrow 4)$ hexosyl-( $1 \rightarrow 4)$-hexosyl-( $1 \rightarrow 4)$-fucosyl-( $1 \rightarrow 2)$-fucosyl (camelose B) (Figure 2).

The ESI-MS/MS showed the deprotonated ion peak at $\mathrm{m} / z 797[\mathrm{M}-\mathrm{H}]^{-}$at Rt $36.11 \mathrm{~min}$ for compound 19 (camelose E), whose $m / z$ was 2 Da more than compound 16 (camelose B). It gave the product ion at $\mathrm{m} / z$ $473[\mathrm{M}-324-\mathrm{H}]^{-}$due to the cleavage of an outer 2 hexose units (lactose moiety). This ion peak (m/z 473) consists of 1 hexose unit (162 Da) and branched pentose moieties $(132+179$ Da). Compound 19 was tentatively named hexosyl-( $1 \rightarrow 4)$-hexosyl-( $1 \rightarrow 4)$-hexosyl- $(1 \rightarrow 4)$ pentosyl-( $1 \rightarrow 2)$-pentosyl (camelose E) (Table 1$)$.

\section{Lipid Peroxidation Measurement and Thiol Group Determination}

All tested concentrations $(0.5 ; 5$ and $50 \mu \mathrm{g} / \mathrm{mL})$ of milk fraction from camel (methanol fraction extracted from raw $\mathrm{CM}$ ) did not drastically reduce plasma lipid autoperoxidation in vitro (Figure 6A). However, the longest incubation time $(60 \mathrm{~min})$ of plasma with milk fraction $(0.5 ; 5$ and $50 \mu \mathrm{g} / \mathrm{mL})$ significantly inhibited plasma lipid autoperoxidation (Figure 6A). The decrease in TBARS level in plasma treated with the highest concentrations ( 5 and $50 \mu \mathrm{g} / \mathrm{mL}$ ) of milk fraction reached about $50 \%$ (Figure $6 \mathrm{~A}$ ).

The results demonstrated that the addition of $\mathrm{H}_{2} \mathrm{O}_{2}$ to human plasma induced oxidative alterations in lipids, but in the presence of 0.5 to $50 \mu \mathrm{g} / \mathrm{mL}$ of milk fraction, the level of TBARS was altered in plasma treated with $\mathrm{H}_{2} \mathrm{O}_{2}$ (Figure 6B). The decrease of TBARS in plasma treated $(60 \mathrm{~min})$ with milk fraction at the highest concentration $(50 \mu \mathrm{g} / \mathrm{mL})$ in the presence of $\mathrm{H}_{2} \mathrm{O}_{2}$ reached about $80 \%$ (Figure $6 \mathrm{~B}$ ). Moreover, the presence of the tested milk fraction from camels effectively diminished autooxidation and $\mathrm{H}_{2} \mathrm{O}_{2}$-stimulated oxidation of thiol groups in human plasma proteins in vitro (Figure 6C). Our results are consistent with the literature. Recently, Ibrahim et al. (2018) studied potential antioxidant bioactive proteins from CM proteins. Reversed-phase HPLC was used for the fractionation of peptides. It was observed that $\mathrm{CM}$ proteins possess antioxidant properties, for example, inhibiting superoxide anion production. The $10 \mu \mathrm{mol} / \mathrm{mL}$ concentration of milk was used. Badr et al. (2017) presented similar properties of CM. Hamzawy et al. (2018) also observed that CM abate oxidative stress (measured by the level of TBARS and activity of various antioxidant enzymes) in a rat model of autism. In addition, results of Meena et al. (2016) have demonstrated that CM ameliorates oxidative damages in type- 1 diabetic experimental rats. For example, CM mildly reduced formation of TBARS in different tissues. Other authors have also indicated that CM reduces oxidative stress (Arab et al., 2014; Hamed et al., 2018). Moreover, not only raw CM, but also its fermented form treated with Lactococcus lactis ssp. cremoris, attenuates the oxidative stress in erythrocytes (Hamed et al., 2018).

\section{CONCLUSIONS}

A key novel finding of this study is a demonstration that the $80 \%$ aqueous methanol fraction from raw $\mathrm{CM}$ 
A

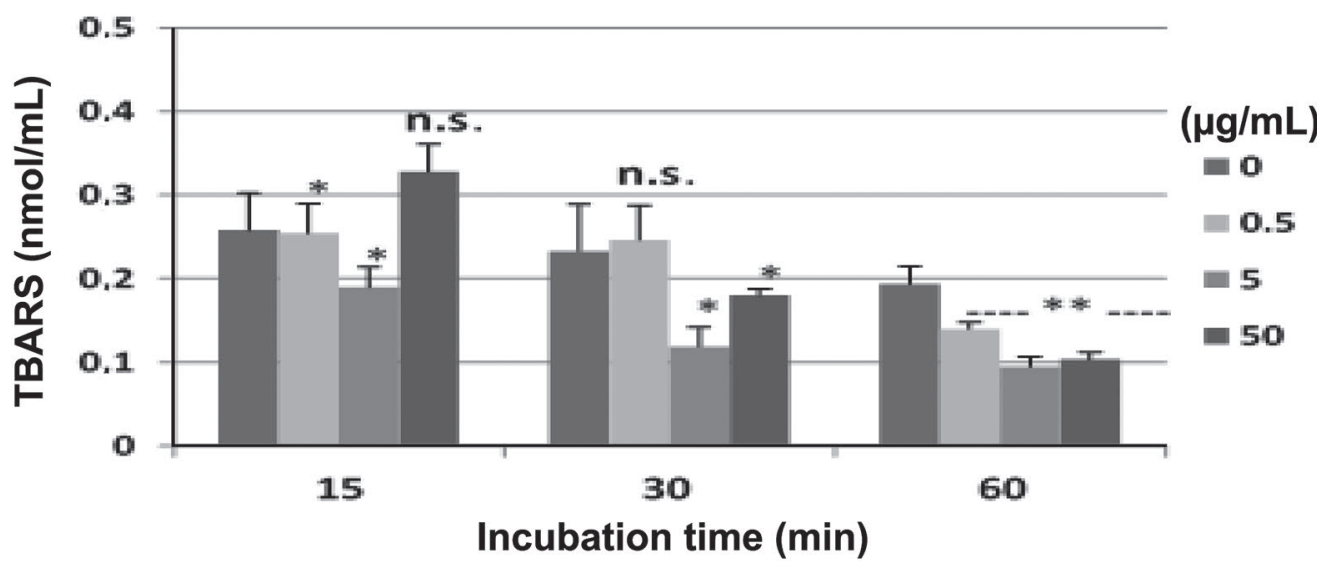

B
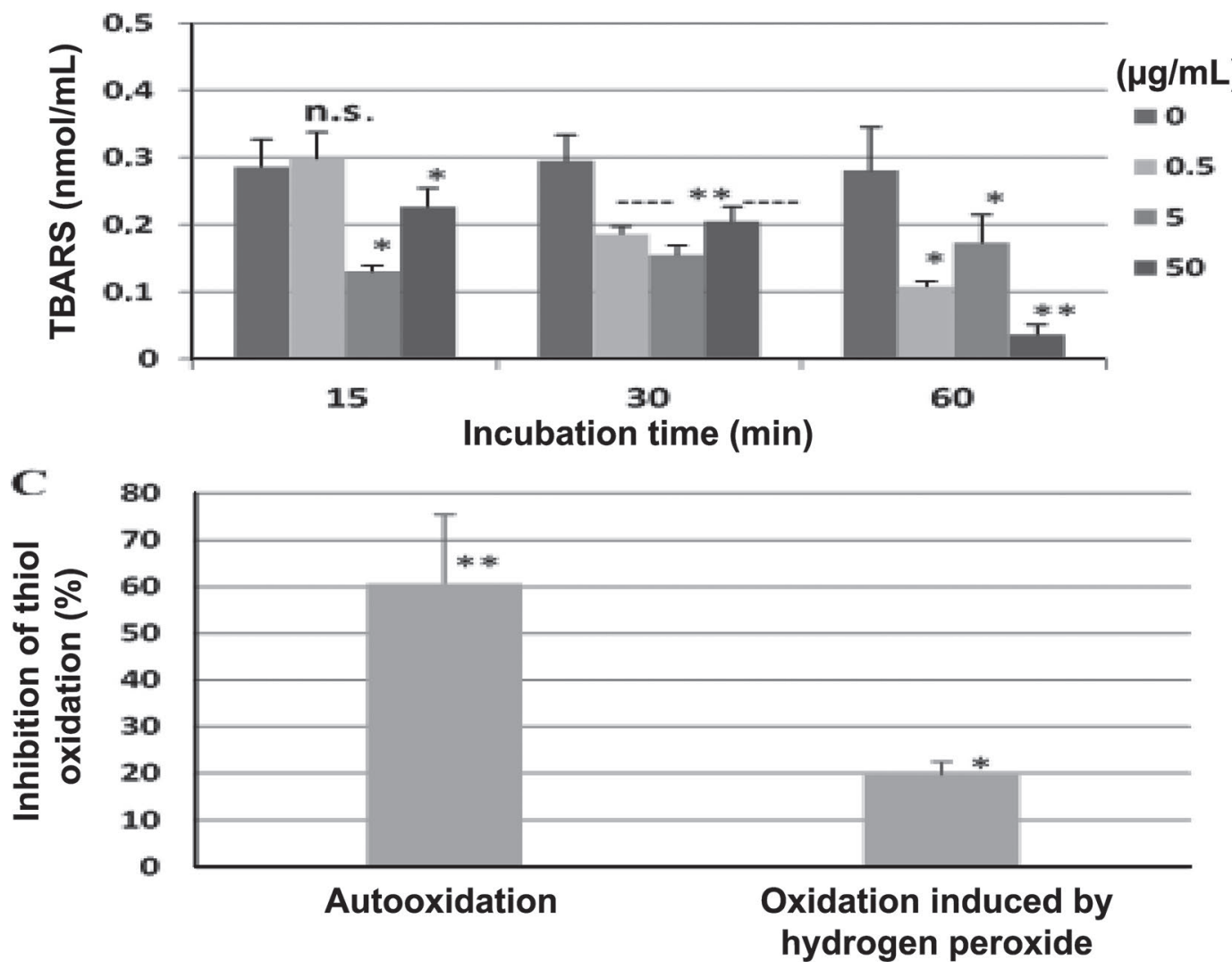

Figure 6. The effects of camel milk fraction (at 3 final concentrations $0.5,5$, and $50 \mu \mathrm{g} / \mathrm{mL}$ for lipid peroxidation; at the final concentration $5 \mu \mathrm{g} / \mathrm{mL}$ for thiol group oxidation) on plasma lipid autoperoxidation (A), lipid peroxidation induced by $\mathrm{H}_{2} \mathrm{O}_{2}$ (B), and plasma thiol group autooxidation (compared with plasma without $\mathrm{H}_{2} \mathrm{O}_{2}$ ) and oxidation induced by $\mathrm{H}_{2} \mathrm{O}_{2}$ (compared with plasma with $\mathrm{H}_{2} \mathrm{O}_{2}$; C). Control negative refers to plasma not treated with $\mathrm{H}_{2} \mathrm{O}_{2}$, whereas control positive to plasma treated with $\mathrm{H}_{2} \mathrm{O}_{2}$. The results are representative of 4 independent experiments and are expressed as means \pm SD. ${ }^{*} P<0.05 ;{ }^{*} P<0.01 ;$ n.s. $P>0.05$. TBARS $=$ thiobarbituric acid reactive substances.

is a complex mixture of polar components such as GSL, LPS, and oligosaccharides, making their resolution and qualification challenging. This qualitative analysis provided a valuable fingerprint of major secondary metabolites occurring in CM. Identification of these compounds through the use of ESI-MS/MS in negative ion mode coupled with liquid chromatography alone eliminates several tedious separation steps. A sequence of linkages of one selected lipopolysaccharide was confirmed by a DFT study, which was considered the back- 
bone of the rest of the LPS. Acquired results revealed that the tested portion is a rich source of GSL, LPS, and oligosaccharides with antioxidant activity. Camel milk may be a promising food product in prophylaxis and treatment of many diseases associated with oxidative stress, including cardiovascular disorders, cancers, and diabetes.

\section{ACKNOWLEDGMENTS}

We are grateful for the specialized Scientific Research Project No. 3269 supported by the Deanship of Scientific Research, Qassim University, Kingdom of Saudi Arabia.

\section{REFERENCES}

Abdalla, O. M., I. A. Wasfi, and F. A. Gadir. 1988. The Arabian race camel normal parameters I. Haemogram, enzymes and minerals. Comp. Biochem. Physiol. A Comp. Physiol. 90:237-239.

Abdel Gader, A. G. M., and A. A. Alhaider. 2016. The unique medicinal properties of camel products: A review of the scientific evidence. Journal of Taibah University Medical Sciences 11:98-103.

Agrawal, R. P., R. Dogra, N. Mohta, R. Tiwari, S. Singhal, and S. Sultania. 2009. Beneficial effect of camel milk in diabetic nephropathy. Acta Biomed. 80:131-134.

Albrecht, S., J. A. Lane, K. Marino, K. A. Al Busadah, S. D. Carrington, R. M. Hickey, and P. M. Rudd. 2014. A comparative study of free oligosaccharides in the milk of domestic animals. Br. J. Nutr. 111:1313-1328.

Al-Haider, A., A. G. Abdel-Gader, and S. A. Mousa. 2011. The antiplatelet activity of camel urine. J. Altern. Complement. Med. 17:803-808.

Alhaj, O. A., and H. A. Al Kanhal. 2010. Compositional, technological and nutritional aspects of dromedary camel milk. Int. Dairy J. 20:811-821.

Alhaj, O. A., E. Taufik, Y. Handa, K. Fukuda, T. Saito, and T. Urashima. 2013. Chemical characterisation of oligosaccharides in commercially pasteurized dromedary camel (Camelus dromedarius) milk. Int. Dairy J. 28:70-75.

Ando, Y., and M. Steiner. 1973a. Sulphydryl and disulphide groups of platelet membranes: Determination of disulphide groups. Biochim. Biophys. Acta 311:26-37.

Ando, Y., and M. Steiner. 1973b. Sulphydryl and disulphide groups of platelet membranes: Determination of sulphydryl groups. Biochim. Biophys. Acta 311:38-44.

Arab, H. H., S. A. Salama, A. H. Eid, H. A. Omar, El-S. A. Arafa, and I. A. Maghrabi. 2014. Camel's milk ameliorates TNBS-induced colitis in rats via downregulation of inflammatory cytokines and oxidative stress. Food Chem. Toxicol. 69:294-302.

Asresie, A., and M. Yusuf. 2014. Traditional consumption, therapeutic value and its derived dairy products of dromedary camel (Camelus dromedaries) milk in Somali Regional State, Eastern Ethiopia: A review. Advances in Life Science and Technology 26:48-52.

Badr, G., N. K. Ramadan, L. H. Sayed, B. M. Badr, H. M. Omar, and Z. Selamoglu. 2017. Why whey? Camel whey protein as a new dietary approach to the management of free radicals and for the treatment of different health disorders. Iran. J. Basic Med. Sci. 20:338-349.

Becke, A. D. 1993. Density-functional thermochemistry. III. The role of exact exchange. J. Chem. Phys. 98:5648-5652.

Bolliger, A., and J. V. Pascoe. 1953. Composition of kangaroo milk (Wallaroo, Macropus robustus). Aust. J. Sci. 15:215-217.

Brewington, C. R., O. W. Parks, and D. P. Schwartz. 1973. Conjugated compounds in cow's milk. J. Agric. Food Chem. 21:38-39.
Brewington, C. R., O. W. Parks, and D. P. Schwartz. 1974. Conjugated compounds in cow's milk. II. J. Agric. Food Chem. 22:293-294.

Cashman, K. D. 2006. Milk minerals (including trace elements) and bone health. Int. Dairy J. 16:1389-1398.

Chen, X., Z. Wang, Y. E. Wong, R. Wu, F. Zhang, and T. D. Chan. 2018. Electron-ion reaction-based dissociation: A powerful ion activation method for the elucidation of natural product structures. Mass Spectrom. Rev. 37:793-810.

Christie, W. W., and X. Han. 2012a. Lipids: Their structures and occurrence. Pages 3-19 in Lipid Analysis. Oily Press, Ayr, Scotland. https://doi.org/10.1533/9780857097866.3.

Christie, W. W., and X. Han. 2012b. Practical identification of individual lipid species in lipid extracts of biological samples. Pages 339-364 in Lipid Analysis. Oily Press, Ayr, Scotland. https://doi .org/10.1533/9780857097866.339.

Conesa, C., L. Sanchez, C. Rota, M. D. Perez, M. Calvo, S. Farnaud, and R. W. Evans. 2008. Isolation of lactoferrin from milk of different species: Calorimetric and antimicrobial studies. Comp. Biochem. Physiol. B Biochem. Mol. Biol. 150:131-139.

Dennis, R. D., S. Baumeister, R. Geyer, J. P. Katalinic, R. Hartmann, H. Egge, E. Geyer, and H. Wiegandt. 1992. Glycosphingolipids in cestodes: Chemical structures of ceramide monosaccharide, disaccharide, trisaccharide and tetrasaccharide from metacestodes of the fox tapeworm, Taenia crassiceps (Cestoda: Cyclophyllidea). Eur. J. Biochem. 207:1053-1062.

Domon, B., and C. E. Costello. 1988. Structure elucidation of glycosphingolipids and gangliosides using high-performance tandem mass spectrometry. Biochemistry 27:1534-1543.

Elkhayat, E. S., G. A. Mohamed, and S. R. M. Ibrahimb. 2012. Activity and structure elucidation of ceramides. Curr. Bioact. Compd. 8:370-409.

FAO. 2013. Dietary protein quality evaluation in human nutrition. FAO Expert Consultation Report, Rome, Italy.

Farwanah, H., and T. Kolter. 2012. Review: Lipidomics of glycosphingolipids. Metabolites 2:134-164.

Fukuda, K., A. Yamamoto, K. Ganzorig, J. Khuukhenbaatar, A. Senda, T. Saito, and T. Urashima. 2010. Chemical characterization of the oligosaccharides in Bactrian camel (Camelus bactrianus) milk and colostrum. J. Dairy Sci. 93:5572-5587.

Galeotti, F., G. V. Coppa, L. Zampini, F. Maccari, T. Galeazzi, L. Padella, L. Santoro, O. Gabrielli, and N. Volpi. 2012. On-line high-performance liquid chromatography fluorescence detectionelectrospray ionization-mass spectrometry profiling of human milk oligosaccharides derivatized with 2-aminoacridone. Anal. Biochem. 430:97-104.

Gangwar, L., D. Narain, A. Khare, and D. Deepak. 2017. Isolation and structure elucidation of novel milk oligosaccharide from Shyama Dhenu (black cow) milk. J. Biol. Chem. Res. 34:188-195.

Gangwar, L., R. Singh, and D. Deepak. 2018. Structure elucidation of a novel oligosaccharide (medalose) from camel milk. J. Mol. Struct. 1153:157-161.

Gill, P. M. W.. Johnson, B. G.. Pople, J. A., and Frisch, M. J. 1992. The performance of the Becke-Lee-Yang-Parr (B-LYP) density functional theory with various basis sets. Chemical Physics Letters 197:499-505.

Habib, H. M., W. H. Ibrahim, R. Schneider-Stock, and H. M. Hassan. 2013. Camel milk lactoferrin reduces the proliferation of colorectal cancer cells and exerts antioxidant and DNA damage inhibitory activities. Food Chem. 141:148-152.

Haddad, I., M. Mozzon, R. Strabbioli, and N. G. Frega. 2011. Electrospray ionization tandem mass spectrometry analysis of triacylglycerols molecular species in camel milk (Camelus dromedarius). Int. Dairy J. 21:119-127.

Hamed, A. I., R. Ben Said, B. Kontek, A. S. Al-Ayedd, M. Kowalczyk, J. Moldoch, A. Stochmal, and B. Olas. 2016. LC-ESI-MS/ MS profile of phenolic and glucosinolate compounds in Samh flour (Mesembryanthemum forsskalei Hochst) and the inhibition of oxidative stress by these compounds in human plasma. Food Res. Int. 85:282-290.

Hamed, A. I., R. Ben Saied, U. A. Mahalel, A. S. Al-Ayed, A. M. Mahmoud, H. A. Elgebaly, A. J. Perez, J. Moldoch, and A. Stochmal. 
2017. Fingerprinting of strong spermatogenesis steroidal saponins in male flowers of Phoenix dactylifera (date palm) by LC-ESI-MS. Nat. Prod. Res. 31:2024-2031.

Hamed, A. I., B. Janda, U. A. Mahalel, A. Stochmal, and W. Oleszek. 2012. Profiles of steroidal saponins from the aerial parts of Tribulus pentandrus, T. megistopterus ssp. pterocarpus and T. parvispinus by LC-ESI-MS/MS. Phytochem. Anal. 23:613-621.

Hamed, A. I., M. Masullo, L. Pecio, D. Gallotta, U. A. Mahalel, S. Pawelec, A. Stochmal, and S. Piacente. 2014. Unusual fernane and gammacerane glycosides from the aerial parts of Spergula fallax. J. Nat. Prod. 77:657-662.

Hamed, H., F. Chaari, Z. Ghannoudi, K. Dhouib, S. Chaabouni, A. El Feki, and A. Gargouri. 2018. Fermented camel milk by Lactococcus lactis ssp. cremoris attenuates erythrocytes oxidative stress-induced hematological and immunological damage in $\mathrm{CCl}_{4^{-}}$ intotiicated mice. Environ. Sci. Pollut. Res. Int. 25:25983-25993.

Hamzawy, M. A., Y. B. El-Ghandour, S. H. Abdel-Aziem, and Z. H. Ali. 2018. Leptin and camel milk abate oxidative stress status, genotoxicity induced in valproic acid rat model of autism. Int. J. Immunopathol. Pharmacol. 32:2058738418785514.

Hsu, F. F. 2016. Complete structural characterization of ceramides as $[\mathrm{M}-\mathrm{H}]^{-}$ions by multiple-stage linear ion trap mass spectrometry. Biochimie 130:63-75.

Ibrahim, H. R., H. Isono, and T. Miyata. 2018. Potential antioxidant bioactive peptides from camel milk proteins. Anim. Nutr. 4:273280.

Ito, E., H. Waki, K. Miseki, T. Shimada, T. A. Sato, K. Kakehi, M. Suzuki, and A. Suzuki. 2013. Structural characterization of neutral glycosphingolipids using high-performance liquid chromatographyelectrospray ionization mass spectrometry with a repeated highspeed polarity and $\mathrm{MS}^{\mathrm{n}}$ switching system. Glycoconj. J. 30:881888.

Jenssen, H., and R. E. Hancock. 2009. Antimicrobial properties of lactoferrin. Biochimie 91:19-29.

Karlsson, N. G., B. L. Schulz, and N. H. Packer. 2004. Structural determination of neutral O-linked oligosaccharide alditols by negative ion LC-electrospray-MS ${ }^{\mathrm{n}}$. J. Am. Soc. Mass Spectrom. 15:659-672.

Keszycha, M. M., G. C. Runowska, P. Lipinska, and J. Wojtowski. 2013. Fatty acid profile of milk- A review. Bull. Vet. Inst. Pulawy 57:135-139.

Konuspayeva, G., É. Lemarie, B. Faye, G. Loiseau, and D. Montet. 2008. Fatty acid and cholesterol composition of camel's (Camelus bactrianus, Camelus dromedarius and hybrids) milk in Kazakhstan. Dairy Sci. Technol. 88:327-340.

Kula, J. 2016. Medicinal values of camel milk. Int. J. Vet. Sci. Res. 2:018-025

Kumar, Y. K., K. Rakesh, P. Lakshmi, and S. Jitendra. 2015. Composition and medicinal properties of camel milk: A review. Asian J. Dairy Food Res. 34:83-91.

Limon, A., J. L. Gallegos-Perez, J. M. Reyes-Ruiz, M. A. Aljohi, A. S. Alshanqeeti, and R. Miledi. 2014. The endogenous GABA bioactivity of camel, bovine, goat and human milks. Food Chem. 145:481-487.

Meena, S., Y. S. Rajput, A. K. Pandey, R. Sharma, and R. Singh. 2016. Camel milk ameliorates hyperglycaemia and oxidative damage in type-1 diabetic experimental rats. J. Dairy Res. 83:412-419.

Merrill, A. H. Jr. 2011. Sphingolipid and glycosphingolipid metabolic pathways in the era of sphingolipidomics. Chem. Rev. 111:63876422 .

Miller, G. D., J. K. Jarvis, and L. D. Mc-Bean. 2000. National Dairy Council. Handbook of Dairy Foods and Nutrition. 2nd ed. CRC Press, Boca Raton, FL.

Mona, E. Y., O. M. Ragia, A. K. H. Abeer, and T. E. Mosa. 2010. Biochemical effects of fermented camel milk on diarrhea in rats. New York Sci. J. 3:106-111.

Morell, C., A. Grand, and A. Toro-Labbe. 2005. New dual descriptor for chemical reactivity. J. Phys. Chem. A 109:205-212.

Nelson, J. C., X. Jiang, I. Tabas, A. Tall, and S. Shea. 2006. Plasma sphingomyelin and subclinical atherosclerosis: Findings from the multi-ethnic study of atherosclerosis. Am. J. Epidemiol. 163:903912 .
Newburg, D. S. 1996. Oligosaccharides and glycoconjugates in human milk: Their role in host defense. J. Mammary Gland Biol. Neoplasia 1:271-283.

Newburg, D. S., and P. Chaturvedi. 1992. Neutral lipopolysaccharides of human and bovine milk. Lipids 27:923-927.

Oursel, S., S. Cholet, C. Junot, and F. Fenaille. 2017. Comparative analysis of native and permethylated human milk oligosaccharides by liquid chromatography coupled to high resolution mass spectrometry. J. Chromatogr. B Analyt. Technol. Biomed. Life Sci. 1071:49-57.

Park, Y. W., and G. F. W. Haenlein. 2006. Handbook of Milk of NonBovine Mammals: Overview of Milk of Non-Bovine Mammals. 1st ed. Blackwell Publishing Ltd., Oxford, UK.

Parodi, P. W. 2006. Nutritional significance of milk lipids. Pages 601639 in Advanced Dairy Chemistry, Volume 2: Lipids, 3rd ed. P. F. Fox and P. L. H. McSweeney, ed. Springer, New York, NY.

Pfenninger, A., M. Karas, B. Finke, and B. Stahl. 2002. Structural analysis of un-derivatized neutral human milk oligosaccharides in the negative ion mode by nano-electrospray / $\mathrm{MS}^{(\mathrm{n})}$. Part 1: Methodology. J. Am. Soc. Mass Spectrom. 13:1331-1340.

Poumale, H., A. Djoumessi, B. Ngameni, L. Sandjo, B. Ngadjui, and Y. Shiono. 2011. A new ceramides isolated from Ficus lutea Vahl (Moraceae). Acta Chim. Slov. 58:81-86.

Puente, R., L. A. Garcia-Pardos, R. Rueda, A. Gil, and P. Hueso. 1994. Changes in ganglioside and sialic acid contents of goat milk during lactation. J. Dairy Sci. 77:39-44.

Redwan, R. M., and A. Tabll. 2007. Camel lactoferrin markedly inhibits hepatitis $\mathrm{C}$ virus genotype 4 infection of human peripheral blood leukocytes. J. Immunoassay Immunochem. 28:267-277.

Robinson, R. C., E. Colet, T. Tian, N. A. Poulsen, and D. Barile. 2018. An improved method for the purification of milk oligosaccharides by graphitised carbon-solid phase extraction. Int. Dairy J. 80:62-68.

Sandjo, L P., and V. Kuete. 2013. Ceramides, cerebrosides, and related long chains containing derivatives from the medicinal plants of Africa. Pages 607-620 in Medicinal Plant Research in Africa: Pharmacology and Chemistry. Elsevier Inc., Amsterdam, the Netherlands. https://doi.org/10.1016/C2012-0-03354-6.

Sbihi, H. M., I. A. Nehdi, and S. I. Al-Resayes. 2013. Characterization of Hachi (Camelus dromedarius) fat extracted from the hump. Food Chem. 139:649-654.

Schulz, B. L., N. H. Packer, and N. G. Karlsson. 2002. Small-scale analysis of O-linked oligosaccharides from glycoproteins and mucins separated by gel electrophoresis. Anal. Chem. 74:6088-6097.

Sharmanov, T. Sh., R. Kh. Kadyrova, O. E. Shlygina, and R. D. Zhaksylykova. 1978. Changes in the indicators of radioactive isotope studies of the liver of patients with chronic hepatitis during treatment with whole camels' and mares' milk. Vopr. Pitan. $1: 9-13$

Singh, A. K., M. Agnihotri, and D. Deepak. 2016. Structure elucidation of novel milk oligosaccharide (Osiose) from sheep milk. J. Biol. Chem. Res. 33:344-351.

Smilowitz, J. T., C. B. Lebrilla, D. A. Mills, J. B. German, and S. L. Freeman. 2014. Breast milk oligosaccharides: Structure-function relationships in the neonate. Annu. Rev. Nutr. 34:143-169.

Srivastava, A. K., P. Singh, and D. Deepak. 2016. Isolation and NMR studies of novel oligosaccharide from goat milk. J. Biol. Chem. Res. 33:381-387.

Thomsson, K. A., H. Karlsson, and G. C. Hansson. 2000. Sequencing of sulfated oligosaccharides from mucins by liquid chromatography and electrospray ionization tandem mass spectrometry. Anal. Chem. 72:4543-4549.

Tonon, K. M., A. Miranda, A. C. F. V. Abrão, M. B. de Morais, and T. B. Morais. 2019. Validation and application of a method for the simultaneous absolute quantification of 16 neutral and acidic human milk oligosaccharides by graphitized carbon liquid chromatography - electrospray ionization - mass spectrometry. Food Chem. 274:691-697.

Urakami, H., M. Saeki, Y. Watanabe, R. Kawamura, S. Nishizawa, Y. Suzuki, A. Watanabe, and K. Ajisaka. 2018. Isolation and assessment of acidic and neutral oligosaccharides from goat milk and 
bovine colostrum for use as ingredients of infant formulae. Int. Dairy J. 83:1-9.

Urashima, T., M. Messer, and O. T. Oftedal. 2016. Oligosaccharides in the milk of other mammals. Pages 45-139 in Prebiotics and Probiotics in Human Milk. M. McGuire, M. McGuire, and L. Bode, ed. Academic Press, London, UK.

Urashima, T., E. Yamaguchi, T. Ohshima, K. Fukuda, and T. Saito. 2018. Chemical structures of oligosaccharides in milk of the raccoon (Procyon lotor). Glycoconj. J. 35:275-286.

Wachowicz, B. 1984. Adenine nucleotides in thrombocytes of birds. Cell Biochem. Funct. 2:167-170.

Ward, R. E. 2009. Isolation of milk oligosaccharides using solid-phase extraction. Open Glycosci. 2:9-15.

Wong, Y. L. E., X. Chen, R. Wu, Y. L. W. Hung, and T. W. D. Chan. 2017. Structural characterization of intact glycoconjugates by tandem mass spectrometry using electron-induced dissociation. Anal. Chem. 89:10111-10117.

Wu, Z., J. Wu, F. Cao, Y. Jin, D. Pan, X. Zeng, and Y. Guo. 2017. Characterization of probiotic bacteria involved in fermented milk processing enriched with folic acid. J. Dairy Sci. 100:4223-4229.
Zancada, L., F. Sanchez-Juanes, J. M. Alonso, and P. Hueso. 2010. Neutral glycosphingolipid content of ovine milk. J. Dairy Sci. 93:19-26.

Zhang, Z., G. Yu, X. Zhao, H. Liu, and H. Guan. 2006. Sequence analysis of alginate-derived oligosaccharides by negative-ion electrospray tandem mass spectrometry. J. Am. Soc. Mass Spectrom. $17: 621-630$.

Zivkovic, A. M., and D. Barile. 2011. Bovine milk as a source of functional oligosaccharides for improving human health. Adv. Nutr. $2: 284-289$.

\section{ORCIDS}

Ridha Ben Said @ $\odot$ https://orcid.org/0000-0003-1500-3178 Bogdan Kontek ( ) https://orcid.org/0000-0002-6098-2494 Mariusz Kowalczyk @ https://orcid.org/0000-0001-7454-4762

Jaroslaw Moldoch ( https://orcid.org/0000-0002-8844-3986

Beata Olas ๑ https://orcid.org/0000-0002-7048-2952 